Document downloaded from:

http://hdl.handle.net/10251/121011

This paper must be cited as:

Li, D.; Hendricks, H.; Han, X.; Jiménez Bello, MA.; Martínez Alzamora, F.; Vereeken, H. (2018). Evaluation of an operational real-time irrigation scheduling scheme for drip irrigated citrus fields in Picassent, Spain. Agricultural Water Management. 208:465-477. https://doi.org/10.1016/j.agwat.2018.06.022

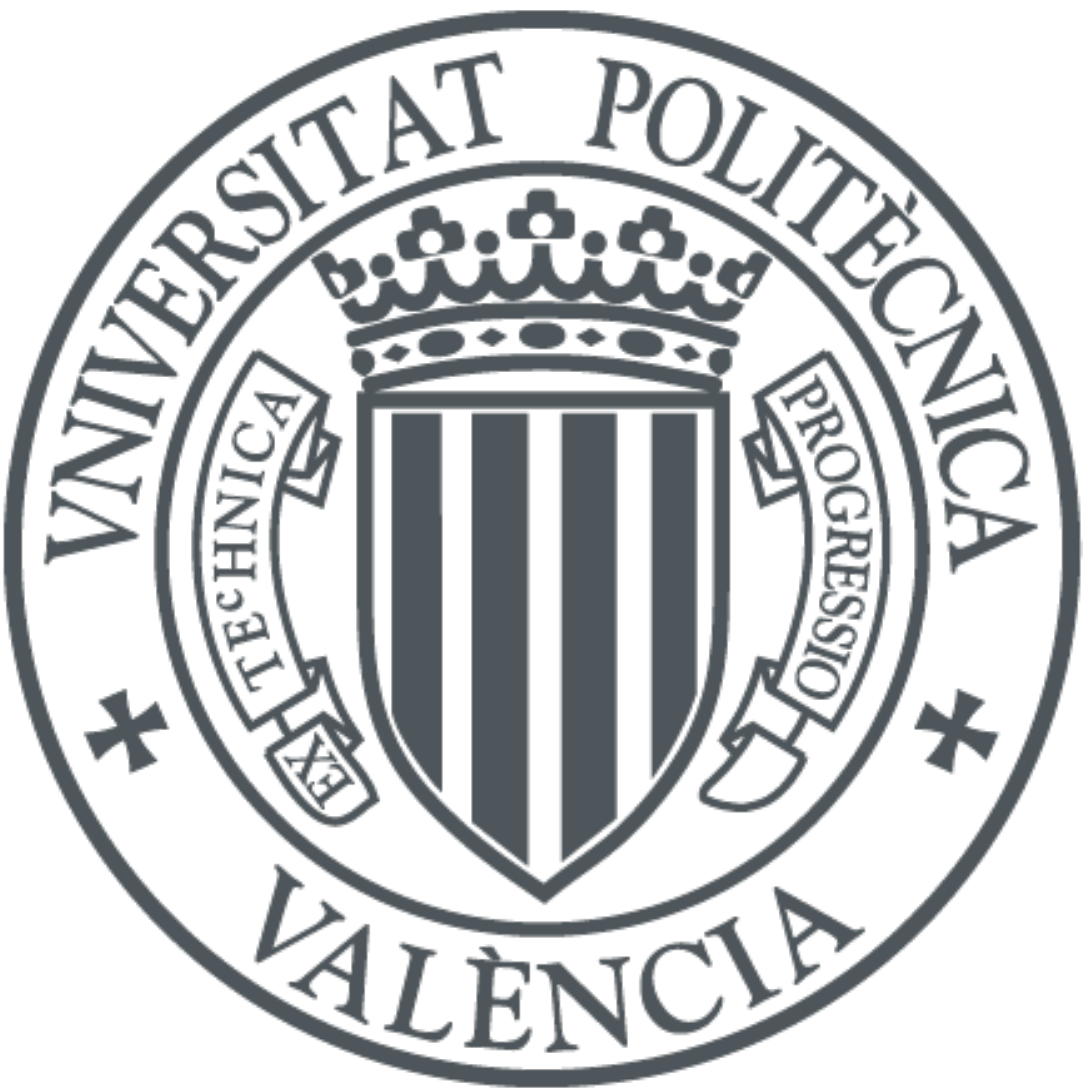

The final publication is available at

http://doi.org/10.1016/j.agwat.2018.06.022

Copyright Elsevier

Additional Information 
See discussions, stats, and author profiles for this publication at: https://www.researchgate.net/publication/326544394

\section{Evaluation of an operational real-time irrigation scheduling scheme for drip irrigated citrus fields in Picassent, Spain}

Article in Agricultural Water Management · September 2018

DOI: 10.1016/j.agwat.2018.06.022

CITATIONS

0

6 authors, including:

Dazhi Li

Forschungszentrum Jülich

4 PUBLICATIONS 16 Citations

SEE PROFILE

Q. Xujun Han

Forschungszentrum Jülich

51 PUBLICATIONS 477 CITATIONS

SEE PROFILE

Some of the authors of this publication are also working on these related projects:
READS

60

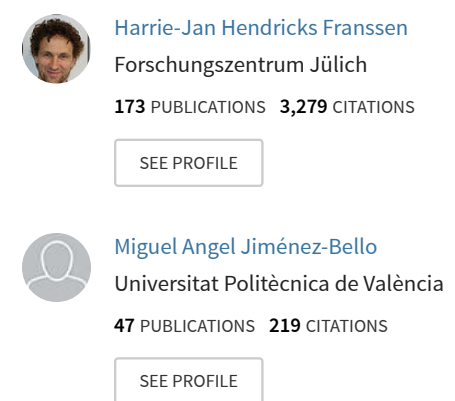

Nuevas herramientas para la gestión técnica de redes de distribución de agua basadas en el modelo matemático y la topología de la red. View project

PhD: Non-invasive monitoring of water and solute fluxes in a cropped soil View project 


\title{
Evaluation of an operational real-time irrigation scheduling scheme for drip irrigated citrus fields in Picassent, Spain
}

\author{
Dazhi Li $^{\mathrm{a}, \text { b, *, Harrie-Jan Hendricks Franssen }}{ }^{\mathrm{a}, \mathrm{b}}$, Xujun Han ${ }^{\mathrm{a}, \mathrm{b}, \mathrm{c}}$, Miguel Angel Jiménez-Bello ${ }^{\mathrm{d}}$, \\ Fernando Martínez Alzamora ${ }^{\mathrm{d}}$, Harry Vereecken ${ }^{\mathrm{a}, \mathrm{b}}$ \\ ${ }^{a}$ Agrosphere (IBG 3), Forschungszentrum Jülich, Leo-Brandt-Strasse, 52425 Jülich, Germany \\ ${ }^{b}$ Centre for High-Performance Scientific Computing in Terrestrial Systems: HPSC TerrSys, Forschungszentrum Jülich, 52425 Jülich, Germany \\ ${ }^{c}$ School of Geographical Science, Southwest University, Tiansheng Road 2 Beibei District, 400715 Chongqing, PR China \\ ${ }^{d}$ Institute of Hydraulic and Environmental Engineering (IIAMA), Universitat Politècnica de Valencia, Camino de Vera s/n, 46022 Valencia, Spain
}

\section{A R T I C L E INFO}

\section{Keywords:}

Irrigation scheduling

Data assimilation

Real-time control

Citrus trees

Land surface model

Stem water potential method

\begin{abstract}
A B S T R A C T
Irrigated agriculture is very important for securing food production for an increasing population over the next decades. Given scarcity of water resources, optimal irrigation management is needed to reduce water while realizing maximal crop productivity. The new method of integrating soil water content measurements and the Community Land Model (CLM) using sequential data assimilation (DA) is promising to improve the prediction of soil water status and efficiently design irrigation strategies. Soil water content measured by FDR (Frequency Domain Reflectometry) was assimilated into CLM by LETKF (Local Ensemble Transform Kalman Filter) to improve model predictions. Atmospheric input data from GFS (Global Forecast System) were used to force CLM in order to predict short-term soil water contents. The irrigation amount was then calculated on the basis of the difference between predicted and targeted soil water content over the root zone.

During the real-time irrigation campaigns in Picassent (Spain) in 2015 and 2016, there were 6 fields irrigated according the data assimilation-optimization approach (CLM-DA), 2 further fields according the FAO (Food and Agriculture Organization) water balance method and also 2 fields traditionally according the farmers preference. The required amount of irrigation water for each citrus field was applied by SCADA (supervisory control and data acquisition system). Compared with the traditionally irrigated fields by farmers, $24 \%$ less irrigation water was needed for the CLM-DA scheduled fields averaged over both years from July to September, while the FAO fields were irrigated with $22 \%$ less water. Stem water potential data and soil moisture recordings of the CLM-DA scheduled fields did not indicate significant water stress during the irrigation period. The CLM-DA scheduled fields received less irrigation water than traditionally irrigated fields, but the orange production was not significantly suppressed.

Overall, our results show that the CLM-DA method is attractive given its water saving potential and automated approach, ease of incorporation of on-line measurements and ensemble based predictions of soil moisture evolution.
\end{abstract}

\footnotetext{
* Corresponding author at: Agrosphere (IBG 3), Forschungszentrum Jülich, Leo-Brandt-Strasse, 52425 Jülich, Germany.

Email address: d.li@fz-juelich.de, lidazhi@lzb.ac.cn (D. Li)
} 


\section{Introduction}

\subsection{Water scarcity and irrigation scheduling}

The world's population has exceeded 7 billion and will continue to increase with a high rate (https://en.wikipedia.org/wiki/World_ population). To feed the increasing population, our agriculture must produce more food. Irrigated agriculture accounts for $40 \%$ of food production, and $70 \%$ of fresh water withdrawals are used by irrigation (Vereechen et al., 2009; Playán and Mateos, 2006). Irrigation is important for the food security of the world (McLaughlin and Kinzelbach, 2015).

Given climate change and increased groundwater pollution, we are facing a global water crisis and stronger constraints on water resources (Vörösmarty et al., 2000; Iglesias and Garrote, 2015). Groundwater recharge in semi-arid areas is usually limited, resulting in unsustainable groundwater use for irrigation and groundwater depletion (Scanlon et al., 2012). Therefore, efficient water use by irrigation scheduling is needed to allocate irrigation water rationally.

Irrigation scheduling aims to minimize water use while maintaining the agricultural production (Evans et al., 1991). Scheduling efforts can have a long-term focus or short-term focus, which includes real-time scheduling (Ticlavilca et al., 2013). With irrigation scheduling we decide when and how much to irrigate. When to irrigate is related to the sensitivity of crops to water stress, which determines the threshold when yield and quality reduction occur under water shortage. How much should be irrigated depends on the water deficit between the current and targeted water status (Evans et al., 1991). In order to make decisions regarding irrigation scheduling, the water stress condition needs to be known. Depending on the type of water stress information available, the irrigation scheduling approaches can be divided into: soil moisture measurements based, evapotranspiration (ET) based and plant water stress based (Evans et al., 1991; Jones, 2004; Pardossi and Incrocci, 2011).

Many devices can give information on soil moisture status including dielectric sensors using Time Domain Transmissivity (TDT) and Frequency Domain Reflectometry (FDR) (Peters et al., 2013), tensiometers (Smajstrla and Locascio, 1996), capacitance probes (Fares and Alva, 2000), neutron probes and cosmic-ray probes (Zreda et al., 2012). The combination of soil moisture information from sensors and predictions by a given model allows to calculate the future water deficit (Blonquist et al., 2006):

The ET based irrigation scheduling calculates the irrigated water amount by the difference between daily actual ET and precipitation (Davis and Dukes, 2010). Evapotranspiration is defined as the sum of evaporation from the soil surface and transpiration from the crop (Allen et al., 1998).

Water stress information from crops can be obtained by different indicators like sap flow (Fernández et al., 2001), stem water potential (Choné et al., 2001) (Fernández and Cuevas, 2010), trunk diameter fluctuation (Moriana et al., 2010), leaf stomata pressure, canopy temperature (Clawson and Blad, 1982) and crop water stress index (CWSI) (Moran et al., 1994).

\subsection{Drip irrigation scheduling for citrus}

Compared with all the major types of surface irrigation (furrow, flood, or large scale sprinkler irrigation), drip irrigation is seen as the most water-efficient and precise method
(Provenzano, 2007). Lots of irrigation scheduling methods were tested on drip irrigated fields on the base of measuring soil or plant water status and evapotranspiration (Dabach et al., 2013). For the drip irrigation of citrus trees, there are plenty of different indicators of plant water stress like stem water potential and soil capacitance, and also several ways to determine evapotranspiration like the FAO method, lysimeter and eddy covariance (EC) method (Jiménez-Bello et al., 2015).

Stem water potential (Sdoodee and Somjun, 2008) and daily trunk shrinkage (Velez et al., 2007) were used to schedule irrigation for citrus orchards world widely. Also the water balance method for drip irrigation scheduling is popular. For example, Sammis et al. (2012) used a two-dimensional soil water balance model for drip irrigation scheduling.

The traditional way of drip irrigation scheduling was often based on a simple water production function or water balance model, while ignoring the complex interaction between soil and vegetation (Barrett and Skogerboe, 1980). A new development is the use of complex models and weather data, combined with mathematical optimization methods (Shang and Mao, 2006). Advanced modeling and programing technology offers a new possibility to calculate soil water status. Various controlling and decision support methods were introduced into irrigation scheduling.

Simulated annealing (Brown et al., 2010), genetic algorithms (Irmak and Kamble, 2009; Wardlaw and Bhaktikul, 2004) and computational neural networks (CNN) (Pulido-Calvo and Gutiérrez-Estrada, 2009) were used to support decisions concerning the irrigated water amount. To predict short or medium scale soil water balance conditions, weather forecast data are also important (Lorite et al., 2015).

In this work, the Community Land Model (CLM) (Oleson et al., 2010) is used to estimate soil and crop water states. Data assimilation (DA) combines direct and/or indirect measurements and dynamic models to get optimal estimates of model states (Reichle, 2008). Han et al. (2016) already illustrated the potential of sequential DA to improve irrigation scheduling with CLM model predictions. In the past already hydrological models like HYDRUS (Autovino et al., 2018) and simpler water balance models (Rallo et al., 2017) were used for irrigation scheduling, but not a land surface model that couples the water and energy cycles. The use of data assimilation in this context is also a novel contribution for the irrigation scheduling of citrus or other fruit trees.

The main objective of this paper is to provide a new approach for irrigation scheduling by introducing the combination of data assimilation and land surface modeling, with the possibility of real-time on-line control and the possibility to ingest different types of measurement data. The CLM-DA method combines model predictions by a land surface model, weather prediction and soil moisture data measured by capacitance probes.

We illustrate our approach for the near real-time irrigation scheduling of citrus trees near Picassent, Valencia (Spain). During the irrigation campaign for the Picassent site (near Valencia, Spain) from July to October in 2015 and June to October in 2016, three different irrigation scheduling methods were tested for 10 citrus fields, including the CLM-DA method proposed in this paper, the FAO water balance model and a traditional method based on farmer's experience. The CLM-DA method combines model predictions by a land surface model, weather prediction and soil moisture data measured by capacitance probes. These information sources are optimally combined using sequential data assimilation, to predict drought 
stress for the next days and schedule irrigation accordingly. The applied irrigation amounts were measured by a water meter, and then divided by the irrigation area to get the water depth. Stem water potential and citrus production indicating the possible water stress were also measured.

\section{Materials and methods}

\subsection{Research site and experimental set-up}

The research site is located near Picassent in Spain $\left(39.38^{\circ} \mathrm{N}\right.$, $0.47^{\circ} \mathrm{E}$ ), in a semi-arid region. Precipitation is concentrated in spring, autumn and winter, and the yearly average precipitation amount is $453 \mathrm{~mm}$, with an annual average daily maximum temperature of $22.3^{\circ} \mathrm{C}$ and an annual average daily minimum temperature of $13.4^{\circ} \mathrm{C}$ (https:// en.wikipedia.org/wiki/Valencia\#Climate). The crop growing at the test site is citrus, with major management procedures like fertilization and weeding carried out by the orchard owners. Although the citrus varieties differ between the fields, there are no significant differences in crop management, fertilization and tree ages. Information on field-specific tree ages were lacking, but all the trees were mature (older than 15 years) and in full-production stage. As precipitation during the main growing period of citrus in summer is rare, the water demand of the citrus trees almost entirely depends on irrigation. Drip irrigation is being used in these citrus tree fields, with two pipelines and 8 10 emitters for each tree. Detailed information about the types of citrus plant, spacing, and vegetative growth character can be found in Table 1.

Within the area of Picassent, the meteorology observatory of IVIA (Instituto Valenciano de Investigaciones Agrarias) provides meteorological data (http://riegos.ivia.es/). Twelve FDR probes were installed in the context of the EU-project AGADAPT since 2013, spreading over the irrigation plots (see Fig. 1), measuring soil water content at four depths $(10 \mathrm{~cm}, 30 \mathrm{~cm}, 50 \mathrm{~cm}$, and $70 \mathrm{~cm})$. During June and July 2015, 12 more FDR probes were installed in the field to enhance the observation density. The FDR probes were installed close to drip emitter and a representative tree of average size in the orchard. The FDR soil water content measurements $(10 \mathrm{~cm}$ and $30 \mathrm{~cm})$ in the irrigated area were used in the DA system for irrigation scheduling, because most roots of citrus trees are located in the top $50 \mathrm{~cm}$. FDR measurements at $50 \mathrm{~cm}$ and $70 \mathrm{~cm}$ depth were later used as independent verification data for possible water depletion. During the irrigation period, the stem water potential was also measured for each field, covering the different irrigation scheduling methods.

Three different irrigation scheduling schemes were compared for this site: irrigation scheduling according (i) CLM-DA calculation (CLM fields), (ii) the FAO water balance model (FAO fields) and (iii) farmers' experiences (Farmer fields). The irrigation scheduling schemes were assigned to different fields in the following way: (1) CLM-DA method: fields CLM-A, CLM-B, CLM-C, CLM-D, CLM-E and CLM-F; (2) FAO water balance: fields FAO-A, FAO-B; (3) farmers' experience: fields Farmer-A, Farmer-B. In June drip irrigation was applied on Monday, Tuesday, Wednesday, Friday and Saturday night (five times per week). In July and August also on Thursday there was irrigation. From September and October onwards, depending on the weather and fruit maturation process, irrigation frequency was reduced and finally stopped. All the experimental fields share the same irrigation frequency while only CLM-DA and FAO fields got suggested irrigation time from the calculations of different methods. The irrigation at the Farmer fields was conducted according the farmer's experience. The irrigation time of Farmer fields ranged from 1 to $2 \mathrm{~h}$ depending on the flow speed and technician's evaluation of water demand for trees.

For the CLM-DA method, there are six fields involved in the irrigation scheduling in 2015 and 2016. Compared with the experiment of 2015, the data assimilation and irrigation controlling process of 2016 were slightly modified to avoid problems which occurred in 2015. As the applied irrigation water amounts in 2015 were affected by the variable flow velocity of the drip line, in 2016 the flow velocity data were retrieved every 3 days, which allowed more accurate irrigation duration so that the truly applied irrigation amount was closer to the scheduled irrigation amount. The needed irrigation amount (which was converted in an irrigation duration) was sent to the technicians in Valencia twice per week to do the real-time control of drip irrigation (period July 7-October 31 2015). In 2016, the irrigation scheduling was from June 1 to October 31 and the corresponding irrigation time was applied directly through SCADA (Supervisory Control And Data Acquisition system) for each CLM-DA field. In 2016 the truly applied irrigation amounts were available shortly after the irrigation was done.

\subsection{FAO soil water balance based irrigation scheduling}

The FAO56 procedure uses the following basic water balance model (Rallo et al., 2011):

Table 1

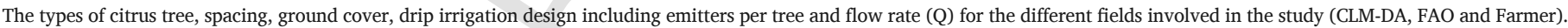

\begin{tabular}{|c|c|c|c|c|c|c|c|}
\hline Fields & Area $\left(\mathrm{m}^{2}\right)$ & Citrus variety & Ground Cover & Row distance (m) & Tree distance (m) & Emitters per tree & $\mathrm{Q}(\mathrm{l} / \mathrm{h})$ \\
\hline CLM-A & 8210 & Valencia Late & 0.33 & 3.5 & 3.5 & 8 & 2.5 \\
\hline CLM-B & 12375 & Hernandina & 0.70 & 4.5 & 5 & 10 & 3.5 \\
\hline CLM-C & 4502 & Clemenules & 0.67 & 4.5 & 5 & 10 & 3.32 \\
\hline CLM-D & 3031 & Clemenules & 0.48 & 5 & 5 & 12 & 5.6 \\
\hline CLM-E & 9573 & Navelina & 0.45 & 6 & 5 & 10 & 1.9 \\
\hline CLM-F & 8978 & Hernanadina & 0.46 & 6 & 4 & 10 & 3.7 \\
\hline FAO-A & 3288 & Lane Late & 0.49 & 4.5 & 3.5 & 10 & 3.9 \\
\hline FAO-B & 5340 & Orogrande & 0.60 & 5 & 5 & 10 & 4.5 \\
\hline Farmer-A & 10583 & Orogrande & 0.60 & 5 & 5 & 10 & 4.4 \\
\hline Farmer-B & 8670 & Hernandina & 0.60 & 5 & 5 & 10 & 2.3 \\
\hline
\end{tabular}




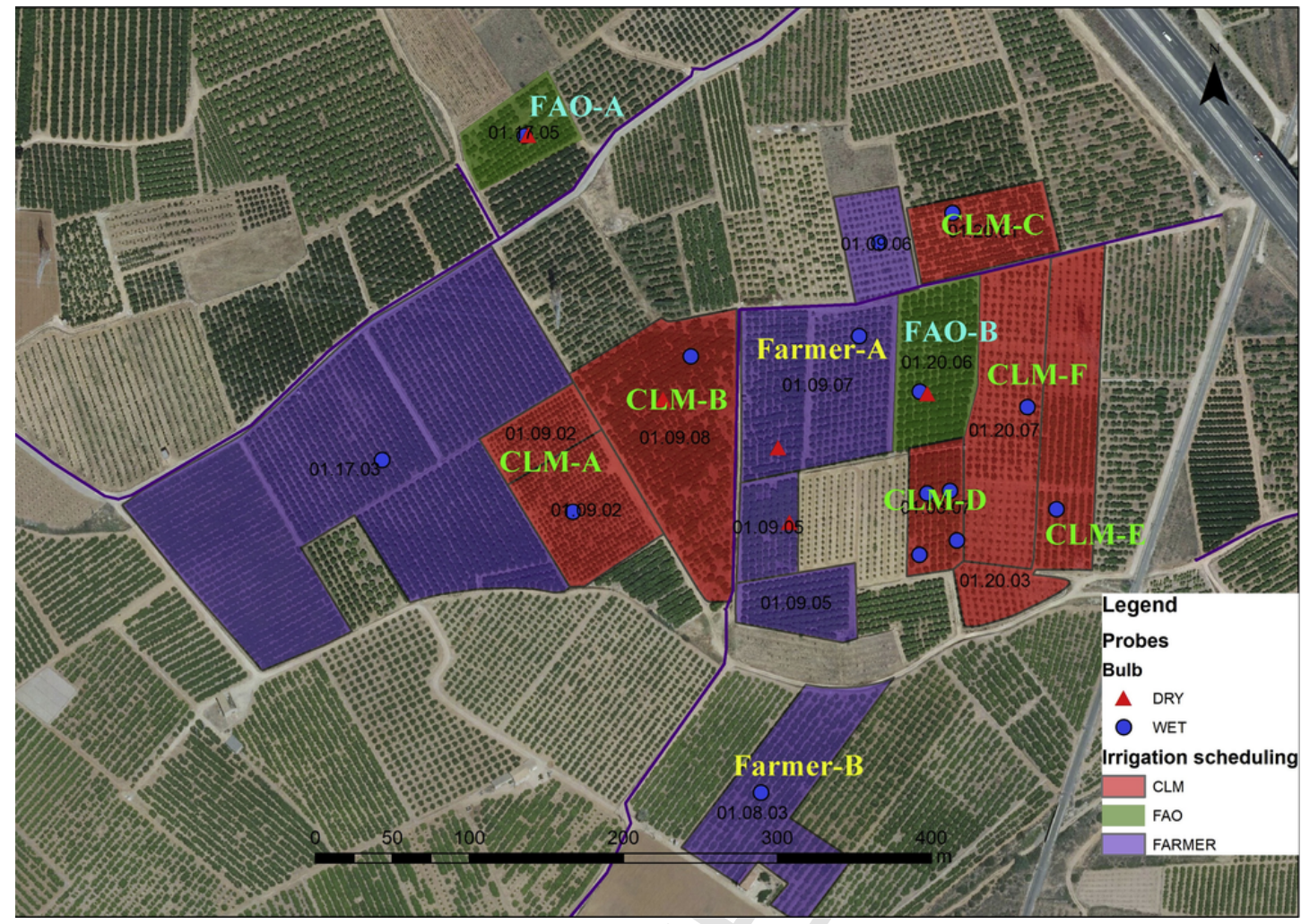

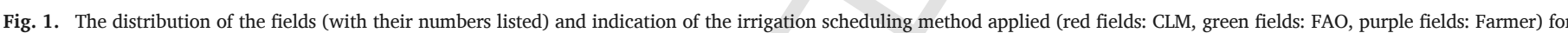

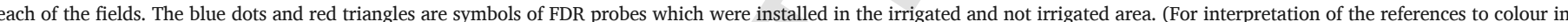
this figure legend, the reader is referred to the web version of this article.)

$$
D_{i}=D_{i-1}+E T_{C}-P_{i}-I_{i}+R_{i}+D P_{i}
$$

where $D_{i}$ is the water depletion at day $i, D_{i-1}$ is water depletion at the previous day $i-1, E T_{C}$ is crop evapotranspiration, $P_{i}$ is precipitation, $I_{i}$ is irrigation, $R_{i}$ is net runoff and $D P_{i}$ is deep percolation. Ideally, runoff can be neglected in flat terrain, and deep percolation is set to zero to avoid water losses (Davis and Dukes, 2010).

The actual crop evapotranspiration $\left(E T_{\mathrm{C}}\right)$ can be calculated from the reference evapotranspiration $\left(E T_{0}\right)$ and the crop coefficient $\left(K_{\mathrm{C}}\right)$.

$$
E T_{C}=K_{C} \cdot E T_{0}
$$

Reference evapotranspiration is calculated by the FAO Penmann-Monteith method (Allen et al., 1998). The crop coefficient may change as function of the vegetation development and the evolution of ground cover, the values of which are available from field experiments or remote sensing (Bausch, 1995).

For the FAO water balance method applied in our fields, the irrigation amount was set equal to the water depletion at previous day $D_{i}$, and the $K_{C}$ was taken to calculate $E T_{C}$ (Castel, 2000):

$$
K_{C}=K_{\text {cavg }} \cdot f_{\text {cm onth }}
$$

$$
K_{\text {carg }}=0.274+G C \cdot 0.005(20 \%<G C<70 \%)
$$

where $K_{\text {cavg }}$ depends on ground cover GC (Miralles et al., 2011) and the $f_{\text {cmonth }}$ is a correction factor which depends on the month of year and is used by the Irrigation Advisory System of Valencia for fruit trees (http: //riegos.ivia.es/).

\subsection{Real-time drip irrigation scheduling by the help of CLM and data assimilation}

\subsubsection{Land surface model}

The Community land model (CLM4.0) is the land surface model of the Community Earth System Model (CESM1.1.2), which describes the ecological and hydrological processes relevant for irrigation optimization and the interaction between the atmospheric boundary layer, soil and vegetation, and is widely used in climate, hydrology and other environmental research (Oleson et al., 2010). A modified Richards equation and Monin-Obukhov similarity theory are used to simulate the soil water flow and land-atmosphere exchange fluxes. The land surface heterogeneity of CLM is represented by 3 levels of sub-grid hierarchy including land units (urban, glacier, lake, wetland and vegetated), columns and 16 plant functional types (PFT) (Oleson et al., 2010).

In this study, in order to use the irrigation model in CLM, each grid cell has two columns: a bare soil non-irrigated column (67\%) and a vegetated irrigated column (33\%). The plant functional type chosen to represent the citrus tree in our model is evergreen broadleaf tree, which has many similarities with citrus trees. The root distribution parameters were modified as 
described by Han et al. (2016) so that most roots are located within $50 \mathrm{~cm}$ soil depth, which is in correspondence with the shallow rooting of irrigated citrus trees as detected by experimental data.

The vertical soil profile in CLM is divided into 15 layers, while only for the upper 10 layers soil water content is calculated. Only these 10 layers will be considered for state updating by data assimilation. The thickness of the CLM layers varies between $1.75 \mathrm{~cm}$ for the first layer and $1.51 \mathrm{~m}$ for the 10th layer (Han et al., 2014). We took the bottom of the third layer $(9.06 \mathrm{~cm}$ depth) and 5 th layer $(28.91 \mathrm{~cm}$ depth) as the counterparts for FDR measurements at $10 \mathrm{~cm}$ and $30 \mathrm{~cm}$ depth.

In CLM, soil hydraulic parameters and soil matric potential are calculated from the sand and clay fractions and in-situ measurement data of soil texture were used for the site (silty clay: silt $33 \%$, clay $32 \%$ and sand $35 \%$ ). The soil hydraulic parameters like saturated hydraulic conductivity are calculated from the Clapp-Hornberger pedotransfer function using as input sand and clay content, as well as organic properties of each soil layer.

\subsubsection{Data assimilation}

Data assimilation is applied in this work to use available soil moisture data to correct predictions by the Land Surface Model CLM in a probabilistic manner. It updates the current system states and should give better estimates of future system states, together with a characterization of the uncertainty of the estimates (Evensen, 2003).

Ensemble Kalman Filter (EnKF) is the Monte Carlo approximation of the Kalman filter that estimates state variables through a forecast and analysis process, where the model covariance matrix is estimated from a limited number of ensemble member which avoids the very expensive explicit computation of the model covariance matrix (Evensen, 2003). In this work, the Local Ensemble Transform Kalman Filter (LETKF) is used, which is a deterministic variant of the Ensemble Kalman Filter. It has been widely used by scientists in land surface hydrology and meteorology (Hunt et al., 2007; Miyoshi et al., 2007; Han et al., 2014, 2015). More details of LETKF can be found in Hunt et al. (2007).

Compared with traditional ensemble Kalman filters, LETKF is more efficient. In LETKF, the global state and observation matrices are only prepared once in a forecast step, then each model grid is updated separately along with the local analysis error covariance matrix, avoiding the calculation of a large error covariance matrix (Han et al., 2014). By dividing the global model grid into separate local patches, each grid cell of the model is updated separately which can be easily exploited in parallel computations (Miyoshi et al., 2007).

In the global operation step of LETKF, two global matrices $\mathbf{X}^{\mathrm{b}}$ and $\mathbf{Y}^{\mathrm{b}}$ are constructed based on soil water content modeled by CLM for each grid cell.

$$
\begin{aligned}
& \mathbf{X}^{\mathrm{b}}=\left[\mathbf{x}_{1}^{\mathrm{b}}-\overline{\mathbf{x}}^{\mathrm{b}}, \ldots, \mathbf{x}_{\mathrm{M}}^{\mathrm{b}}-\overline{\mathbf{x}}^{\mathrm{b}}\right] \\
& \mathrm{Y}^{\mathrm{b}}=\left[\mathbf{y}_{1}^{\mathrm{b}}-\overline{\mathbf{y}}^{\mathrm{b}}, \ldots, \mathbf{y}_{\mathrm{M}}^{\mathrm{b}}-\overline{\mathbf{y}}^{\mathrm{b}}\right]
\end{aligned}
$$

$$
\mathbf{y}_{1}^{\mathrm{b}}=\mathbf{H}\left(\mathbf{x}_{\mathrm{i}}^{\mathrm{b}}\right)
$$

where $\mathbf{x}_{1}^{\mathrm{b}} \ldots \mathbf{x}_{\mathrm{M}}^{\mathrm{b}}$ contain the modeled states for the $M$ ensemble members ( $M=20$ in this work), $\overline{\mathbf{x}}^{\mathrm{b}}$ is the ensemble mean; $\mathbf{y}_{1}^{\mathrm{b}} \ldots \mathbf{y}_{\mathrm{M}}^{\mathrm{b}}$ are vectors containing the model states at the observation locations for each of the $M$ ensemble members, $\overline{\mathbf{y}}^{\mathrm{b}}$ is the vector of the corresponding ensemble means and $\mathbf{H}$ is the observation operator that maps between the model space and the observation space, which is the identity matrix in our case because of the direct observation. The model state vector $\mathbf{x}^{\mathrm{b}}$ is constructed as:

$\mathbf{x}^{\mathbf{b}}=\left[\theta_{1}, \theta_{2} \ldots \theta_{10}\right]^{T}$

where $\theta_{1}, \theta_{2} \ldots \theta_{10}$ are modeled soil water contents for the ten CLM layers.

In the local analysis step, the analysis error covariance matrix $\widetilde{\mathbf{P}}^{a}$ is calculated as:

$$
\widetilde{\mathbf{P}}^{a}=\left[(M-1) \mathbf{I}+\left(\mathbf{Y}^{\mathrm{b}}\right)^{\mathrm{T}} \mathrm{R}^{-1} \mathrm{Y}^{\mathrm{b}}\right]^{-1}
$$

where $\mathbf{R}$ is the observation error matrix, with values equal to $(0.01)^{2}$ on the diagonals and zero values for the other matrix elements as correlations between measurement errors are not considered; $\mathbf{I}$ is the identity matrix.

The perturbations matrix $\mathbf{W}^{a}$ and analysis mean $\overline{\mathbf{w}}^{a}$ are calculated as:

$$
\begin{aligned}
& \mathbf{W}^{a}=\left[(M-1) \widetilde{\mathbf{P}}^{a}\right]^{1 / 2} \\
& \overline{\mathbf{w}}^{\mathrm{a}}=\widetilde{\mathbf{P}}^{\mathrm{a}}\left(\mathbf{Y}^{\mathrm{b}}\right)^{\mathrm{T}} \mathbf{R}^{-1}\left(\mathbf{y}^{0}-\overline{\mathbf{y}}^{\mathrm{b}}\right)
\end{aligned}
$$

where $\mathbf{y}^{0}$ is the observation vector containing soil water content measured by the FDR sensors and for the different layers.

Finally the new analysis matrix $\mathbf{X}^{\mathrm{a}}$ that contains the updated ensembles in model space is obtained by:

$\mathbf{X}^{\mathrm{a}}=\overline{\mathbf{x}}^{\mathrm{b}}+\mathbf{X}^{\mathrm{b}}\left(\mathbf{W}^{\mathrm{a}}+\overline{\mathbf{w}}^{\mathrm{a}}\right)$

Localization implementation implies that each model grid cell is only updated by the closest FDR sensor observation. Ensemble inflation is also used in LETKF to prevent filter divergence (Han et al., 2014). In this work, only the model grid cells with FDR observations were updated by data assimilation while soil and vegetation parameters are pre-defined and taken from in-situ measurements and LAI data respectively. The LAI values were calculated based on the ground coverage (GC) and an empirical function derived from field measurements. A more detailed description of the data assimilation with LETKF and CLM can be found in Han et al $(2015,2016)$.

$\mathrm{LAI}=-1.3 \cdot \log \left(\frac{(1-G C)}{1+G C}\right)$

\subsubsection{CLM-DA irrigation scheduling}

After the data assimilation analysis, the updated initial model states in the form of soil water content values are used 
as input for predicting the evolution of soil water content values for the next 3 or 4 days. This is done for each of the model ensemble members so that also the uncertainty of the predictions can be characterized. These predictions use weather forecasts as input. On the other hand, a target soil water status is defined to sustain crop growth and yield. The difference between the predicted soil water status and the target soil water status is the water deficit, and irrigation scheduling is planned on the basis of the calculated water deficit. In CLM, the target soil water content can be defined for the irrigation needs of different crops (Oleson et al., 2010):

$\theta_{\text {target }}=(1-0.7) \cdot \theta_{\min }+0.7 \cdot \theta_{\max }$

where $\theta_{\min }$ is the minimum needed soil water content to sustain completely open stomata and $\theta_{\max }$ is soil saturation. They are defined separately for each soil layer. The empirical parameter 0.7 was set in CLM to match the calculated global irrigation demand for the year 2000 with the observation data (Oleson et al., 2010).

The irrigation amount ( $W_{\text {deficit }}$ ) is calculated by the integrated water deficit over the root zone (Oleson et al., 2010):

$W_{\text {deficit }}=\sum_{i}^{N} R_{i} \cdot \max \left(\theta_{\text {target }}-\theta_{i}, 0\right)$

where $\theta_{i}$ is the soil water content for layer $i, R_{i}$ is the root fraction for that layer, and $N$ is the number of CLM-layers with roots, which are dependent on the plant functional type (PFT) in CLM.

$$
R_{i}= \begin{cases}0.5\left[\begin{array}{ll}
\left.\exp \left(-r_{a} Z_{k,-1}\right)+\exp \left(-r_{b} Z_{k, i-1}\right)\right] \\
-\exp \left(-r_{a} Z_{k, i}\right)+\exp \left(-r_{b} Z_{k, i}\right)
\end{array}\right] & 1 \leq i<N \\
0.5\left[\exp \left(-r_{b} Z_{k, j-1}\right)+\exp \left(-r_{b} Z_{k, i-1}\right)\right] & i=N_{k \text { wsoi }}\end{cases}
$$

where $Z_{h, i}(\mathrm{~m})$ is the depth from the surface to the interface between soil layers $i$ and $i+1, r_{a}$ and $r_{b}$ (both are 8.992 for citrus) are root distribution parameters for different plants (Zeng, 2001).

Forecasted weather data were used as input to the land surface model for soil water status predictions. The T1534 Semi-Lagrangian grid weather forecast data $\left(0.25^{\circ}\right)$ were downloaded from the NCEP Global Forecast System (GFS) product (http://www.nco.ncep.noaa.gov/ $\mathrm{pmb} /$ products/gfs/) inventory twice per week. For land surface model predictions and irrigation scheduling from Monday to Wednesday the GFS-forecast from Sunday was used, whereas for land surface model predictions and irrigation scheduling from Thursday to Sunday the forecast from Wednesday was taken. One GFS-pixel covers our complete simulation domain and was therefore applied to all CLM grid cells. The original GFS data were interpolated from 3-h intervals to 1-h intervals. In the irrigation scheduling campaign of 2016, irrigation was not applied if the forecasted precipitation amount was larger than $5 \mathrm{~mm}$.

\subsection{Stem water potential, deep soil water content measurements and production data}

We had three independent data sources to evaluate water stress by the trees: (i) stem water potential measurements; (ii) deep soil water content measurements, and (iii) production data. These sources of information will be discussed in addition.

During the irrigation campaign, stem water potential (SWP) was measured with pressure chamber equipment (Model 600 Pressure Chamber, PMS Instrument Company, Albahy, USA) by following the method descried by Turner (1981). Even though the stem water potential has no direct quantitative relation with the soil water content, it is a sensitive indicator of crop water stress and can be used to evaluate the water deficit condition of the fields. In the irrigation periods, stem water potential was measured every 2 weeks at noon with a sample of 5 trees per field and 4 leaves per tree. They were chosen from at least three different emitter lines and always including the tree where the FDR probe was placed. After $2 \mathrm{~h}$ in the plastic bag, leaf water potential will be equal to the stem water potential. Then the leaves were sealed into the air chamber with a part of petiole exposed outside. The increased air pressure that makes water coming out from the cut surface of petiole is considered as the water tension within the leaves. The measured value of water potential is normally negative, which symbolizes the level of water stress and water deficit of the plants. Low stem water potential may cause the closure of stomata, the commonly used threshold is $-1.5 \mathrm{MPa}$ (Blonquist et al., 2006).

Soil water content measured by FDR sensors at $50 \mathrm{~cm}$ and $70 \mathrm{~cm}$ depth was not used in the data assimilation, but was used as a further indicator of possible water stress. The drop of deep soil water content in the irrigation season is linked to the possibility that not enough drip irrigation is applied.

The fruit production data for each field were also collected at the end of the season to support the evaluation. The production is the commercial yield that farmers sold to cooperatives. Unfortunately, not for all fields production data could be obtained as not all farmers collected this information. Reduced fruit production can be another indicator of the existence of water stress during the past growing season, but there are other possible explanations for a relatively small fruit production not related to drought stress.

\subsection{Statistical analysis of the performance of the irrigation scheduling methods}

The predictions by the models were evaluated by the Root Mean Square Error (RMSE) according to:

$\mathrm{RMSE}=\sqrt{\frac{\sum_{t=1}^{n}\left(\theta_{m}-\theta_{s}\right)^{2}}{n}}$

where $\theta_{m}$ is the CLM modeled soil water content, $\theta_{s}$ soil water content measured by FDR probes and $n$ is the number of time steps within the modeling period.

In order to explore the efficiency of the CLM-DA based irrigation, the irrigation amounts for the different fields (CLM-DA method, FAO-method and Farmer approach) were compared. The applied water volume was divided by the area $\left(\mathrm{m}^{2}\right)$ of each field, and the water depth $(\mathrm{mm})$ for each irrigation day was calculated. Possible drought stress was analyzed with help of the data from the stem water potential campaigns, fruit production measured at the end of the season and measured soil water content at $50 \mathrm{~cm}$ and $70 \mathrm{~cm}$ depth, which were not assimilated.

Integrated stem water potential (ISWP) was calculated based on the following function (García-Tejero et al., 2010): 
$\mathrm{ISWP}=\sum_{i=1}^{i=t} P_{i+1}\left(n_{i+1}-n_{i}\right)+\frac{1}{2}\left(P_{i}-P_{i+1}\right)\left(n_{i+1}-n_{i}\right)$

where $P_{i}$ and $P_{i+1}$ are midday stem water potential measurements at day $i$ and day $i+1$ day, $\left(n_{i}+1-n_{i}\right)$ is the interval in days between two measurements ( 14 days for our fields), $t$ is the integration time.

We also calculated the Seasonal Irrigation Performance Indicator (SIPI) for the period July-September, which is potentially most affected by drought stress, for the years 2015 and 2016. SIPI is an indicator for the water saving performance of each irrigation method. It was calculated as ratio between actual evapotranspiration $\left(E T_{C}\right)$ and the incoming water flux (irrigation water and rainfall) in the same period. Therefore, irrigation amount and $E T_{0}$ and $E T_{C}$ were determined for these periods, with $K_{\mathrm{C}}$ factor derived by the method in Section 2.2 .

A statistical analysis was performed on the basis of measured integrated stem water potentials, soil water contents, irrigation amount, commercial fruit production and irrigation performance index. We calculated Pearson correlation coefficients between variables, and analyzed (linear) relationships between variables.

\section{Results and discussion}

\subsection{Selection of the fields for evaluation in 2015 and 2016}

Three CLM fields (CLM-D, CLM-E, CLM-F) were excluded from the analysis in 2015, as for those fields the scheduled irrigation scheme was not followed. Fig. 2 illustrates the comparison between scheduled and real-applied irrigation amounts, including the three inconsistent CLM fields. In two cases the farmers did not follow the recommended irrigation amount, and in one case flow velocity in the irrigation

system
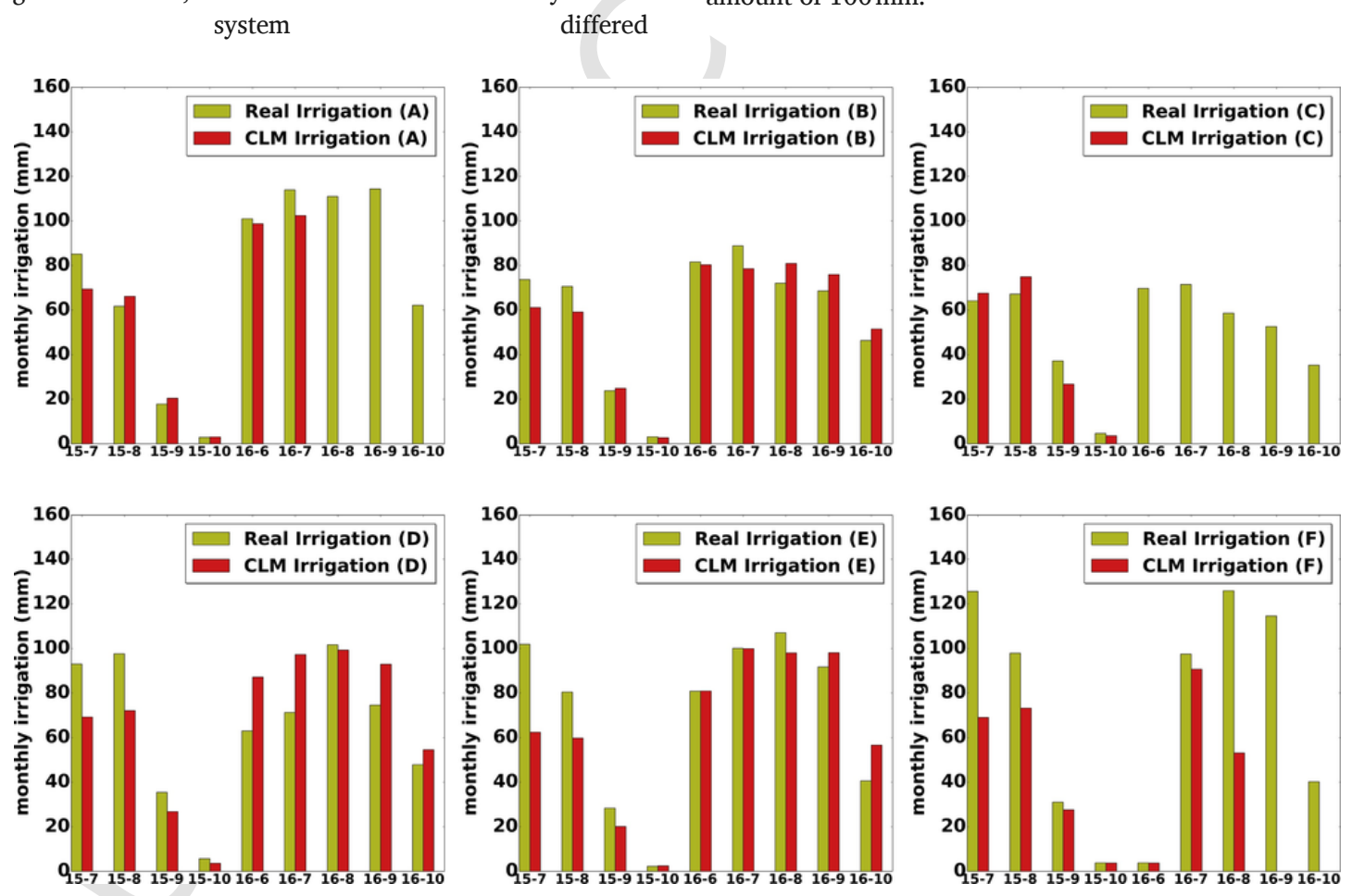

Fig. 2. Comparison of irrigation amounts calculated for CLM-DA and truly applied irrigation amounts for all CLM-DA (A F) fields in 2015 and 2016. 


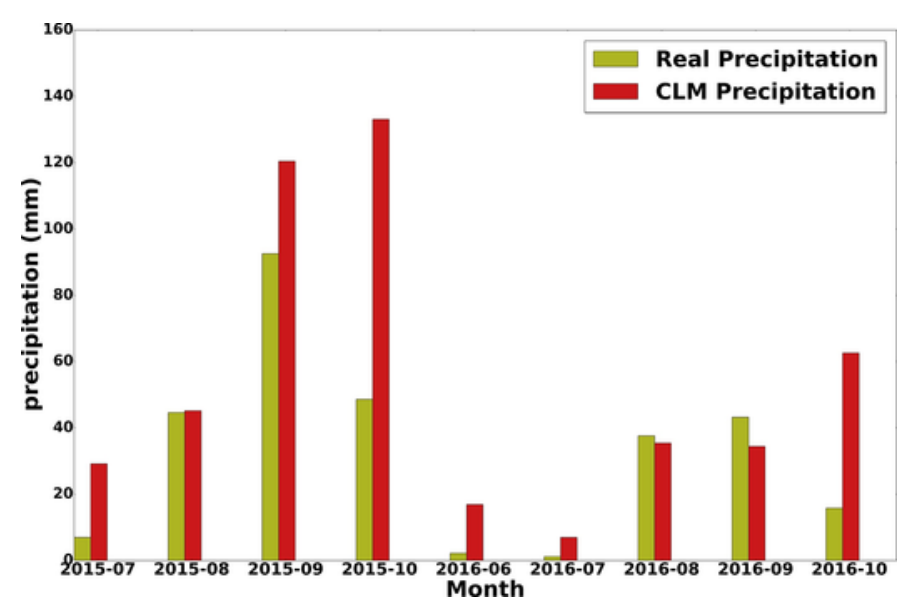

Fig. 3. Comparison of forecasted and measured monthly precipitation for 2015 and 2016.

In October (both in 2015 and 2016) the forecasted precipitation was much higher than the observed one. The forecast biases in 2015 and 2016 were mainly related to October. In October, larger precipitation amounts are related to mesoscale systems which form over the relatively warm Mediterranean Sea and it seems that the prediction of the precipitation associated with those systems was more difficult.

\subsection{Stem water potential and deep layer soil water centent data for the evaluation of water stress}

Previous research for citrus trees suggested that the minimum water potential value at wilting point can be down to $-1.7 \mathrm{MPa}$ for young leaves, and $-1.9 \mathrm{MPa}$ to $-2.6 \mathrm{MPa}$ for mature leaves (Syvertsen also reported that citrus trees under regulated deficit irrigation can have a threshold stem water potential of $-1.84 \mathrm{MPa}$ (Ballester et al., 2014). So we got the conclusion that if stem water potential is lower than $-1.8 \mathrm{MPa}$ a negative impact on citrus trees is expected. As shown in Fig. 4, in 2015 two of the CLM-DA fields (CLM-A, CLM-B) may have experienced water stress at one measurement day in August, and this was also the case for one FAO field (FAO-B). This water stress might be related to the high water vapor pressure deficit that day, which might have resulted in stomata closure irrespective of irrigation amount and soil water status (Ballester et al., 2011). From June to October in 2016, Fig. 4 indicates the possible water stress in July for field CLM-D, related to irrigation scheduling which did not follow the CLM-DA suggestions and was too low. At the end of October, with the harvest season coming for some fields and given predicted precipitation events, the irrigation was stopped by the technicians resulting again in drought stress. In all other cases there was no drought stress according to these measurements.

As shown in Fig. 5, soil water measured at $50 \mathrm{~cm}$ and $70 \mathrm{~cm}$ depth for the three CLM fields did not show a decreasing trend over the irrigation season in 2016, which implies that irrigation was not too small, which would cause decrease of soil water contents. Soil water contents measured at $50 \mathrm{~cm}$ and $70 \mathrm{~cm}$ depth for the fields irrigated according the FAO and Farmer methods did not show a decreasing trend either.

\subsection{Statistical analysis}

\subsubsection{Validation of the CLM-DA system}

The observed and modeled soil water contents (SWC) at 10 and $30 \mathrm{~cm}$ depth for one of the CLM fields are shown in Fig. 6. The assimilation of FDR measurements significantly improved the SWC-characterization at 10 and $30 \mathrm{~cm}$ depth. Table 2 illuset al., 1981; Syvertsen, 1982). It is
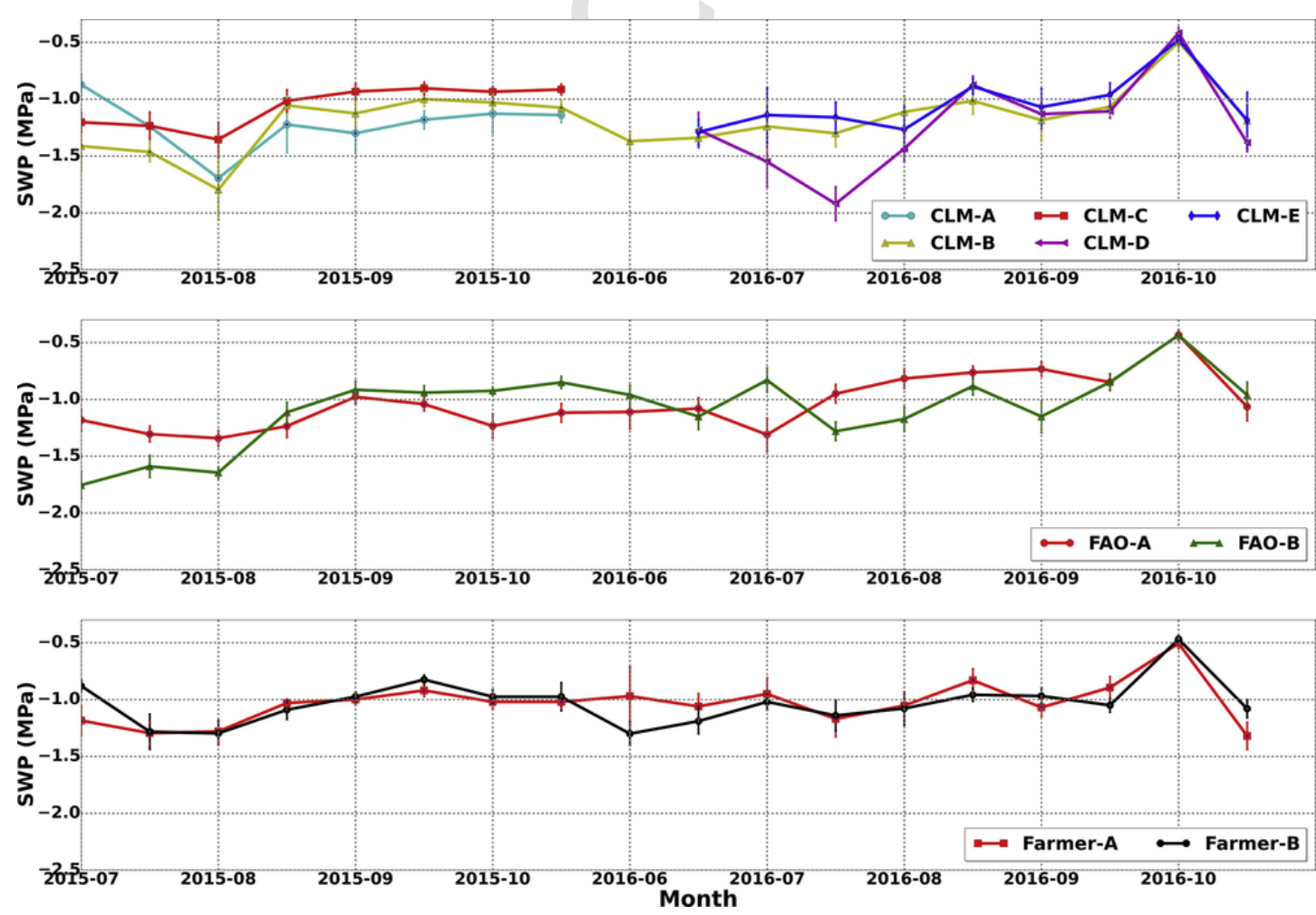

Fig. 4. Stem water potential measurements (including error bars for standard deviation) for CLM fields, FAO fields and Farmer fields in 2015 and 2016. 

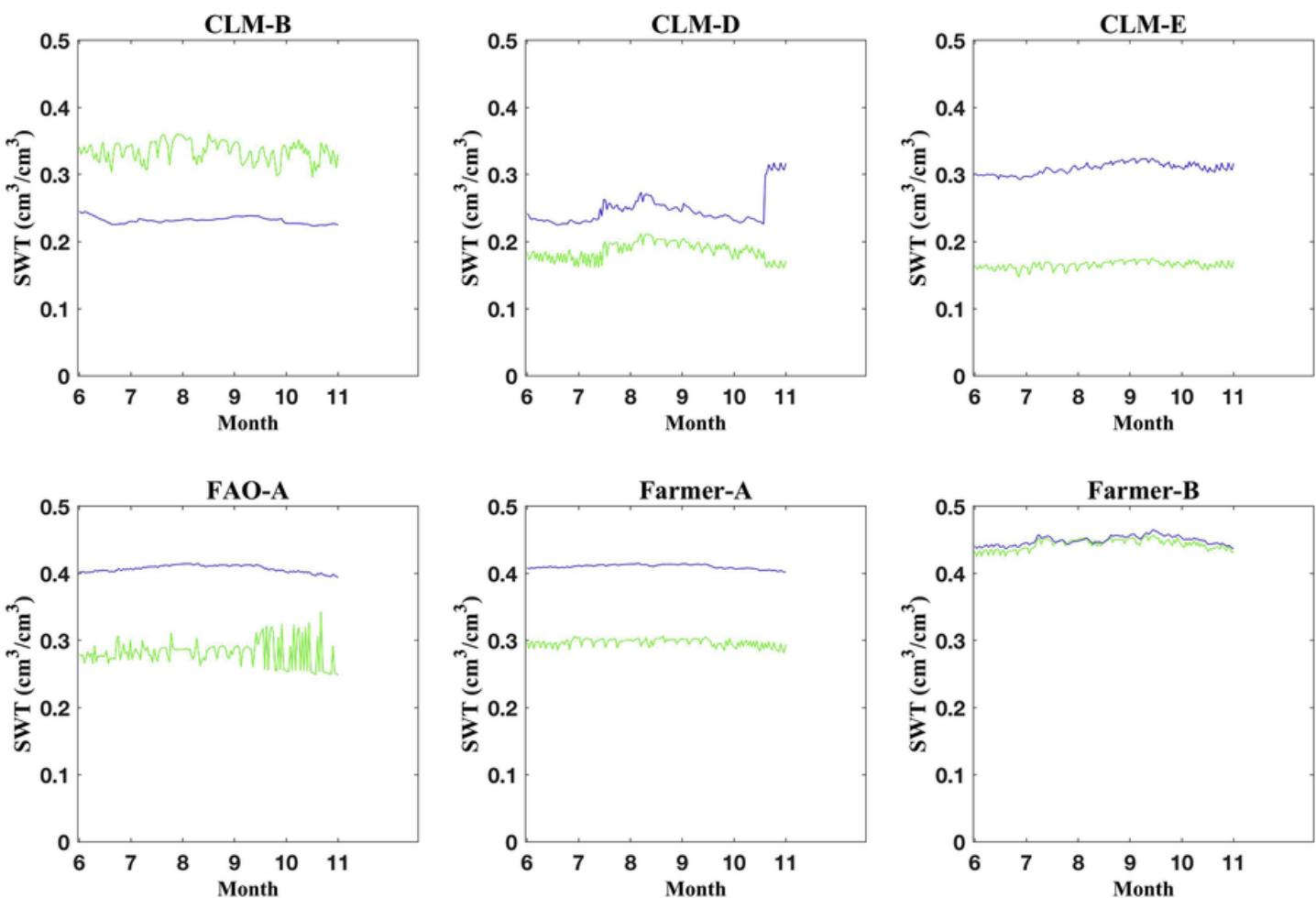

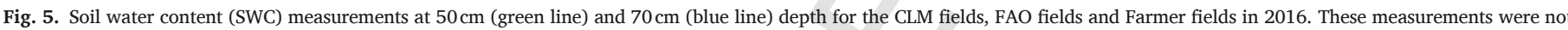
used in the assimilation. (For interpretation of the references to colour in this figure legend, the reader is referred to the web version of this article.)
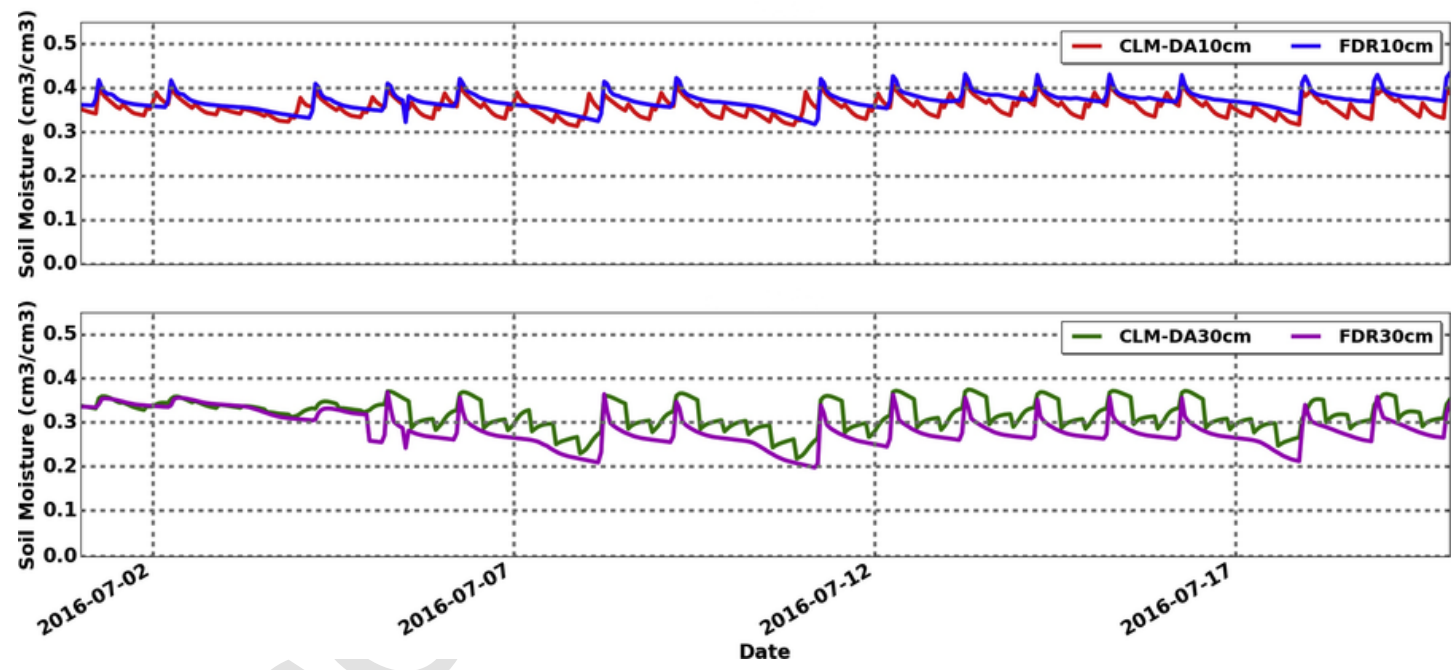

Fig. 6. Comparison of soil water content modeled by CLM and measured by FDR (field CLM-B) at 10 and $30 \mathrm{~cm}$ depth for the year 2016 .

Table 2

Comparison of RMSE $\left(\mathrm{cm}^{3} / \mathrm{cm}^{3}\right)$ between simulated and measured SWC for the CLM fields (N.A. is no data).

\begin{tabular}{|c|c|c|c|c|c|c|}
\hline Fields & CLM-A & CLM-B & CLM-C & CLM-D & CLM-E & CLM-F \\
\hline 2015 & 0.02 & 0.022 & 0.04 & 0.034 & 0.03 & 0.025 \\
\hline 2016 & N.A. & 0.037 & N.A. & 0.021 & 0.031 & N.A. \\
\hline
\end{tabular}

trates that the RMSE for SWC at 10 and $30 \mathrm{~cm}$ depth is smaller than $0.04 \mathrm{~cm}^{3} / \mathrm{cm}^{3}$ for all the 6 fields in 2015 . However, some of the fields show a relatively high RMSE compared to others.
As only states but no parameters were updated, a systematic bias of soil properties can be expected, affecting also soil water contents. 
Unfortunately, for the experiments in 2016 three CLM-DA experiments could not be considered in the analysis as discussed in Section 3.1. Therefore, the RMSE of SWC for those fields could not be calculated and is symbolized as N.A. in Table 2.

\subsubsection{Water consumption data and irrigation performance}

Irrigation records for the three irrigation scheduling methods are presented in Table 3 and Figs. 7 and 8. Overall, the CLM fields were irrigated with a smaller water amount than the Farmer fields. In 2015 the water saving performance was even better than the FAO method (9\% less irrigation water for CLM than for FAO and 21\% less for CLM than for Farmer fields). Table 3 shows that in average the accumulated irrigation depths in 2016 are slightly larger for the CLM-DA fields $(341 \mathrm{~mm})$ than for the fields following the FAO method $(337 \mathrm{~mm})$, but again smaller than for the Farmer fields $(424 \mathrm{~mm})$. The averaged seasonal irrigation performance index (SIPI) for 3 CLM fields in 2015 was larger than for the FAO fields ( 0.71 for CLM and 0.64 for FAO), suggesting better water saving performance. In 2016 the averaged SIPI for CLM and FAO fields showed no differences (both are 0.66 ), and were both larger than for the Farmer fields (0.56).

Taking the average over both years and the three months of July, August and September, the CLM fields received 24\% less irrigation water than the fields irrigated according the Farmer method, while the FAO fields were irrigated with $22 \%$ less water than the Farmer method. Meanwhile, the fruit production data showed that the CLM fields had a slightly smaller production, but given the large variation between the fields this is not significant. In 2016, due to heavy precipitation and strong winds in the harvest period (November and December), all the fields suffered production loss irrespective of the irrigation method.

Fig. 7 shows that the irrigation amounts vary less between the different months for the CLM fields than for the FAO fields. Although the differences in irrigation amount between the fields are large, all the fields show a similar trend in the monthly irrigation amounts, with largest irrigation amounts for the months of June until August.

The temporal dynamics of irrigation depth, $E T_{0}, E T_{C}$ and precipitation for the different fields which are irrigated according different methods are displayed in Fig. 8 (except CLM-fieds which were excluded from the analysis, see Section 3.1$)$. The daily maximum temperature $\left(\mathrm{T}_{\max }\right)$, minimum temperature $\left(\mathrm{T}_{\min }\right), E T_{0}$ and precipitation were also shown in Fig. 8. The $E T_{C}$ was calculated by meteorological data assuming a $K_{C}$ factor of 0.68 , a typical value for citrus tree. Precipitation amounts were higher in 2015 resulting in a higher irrigation demand than in 2016 for all fields, irrespective of the irrigation method. In particular the larger amounts of precipitation in September and October 2015 resulted in a temporary irrigation stop and the overall smaller applied irrigation amounts than in 2016.

\subsubsection{Correlations between different environmental variables}

Table 4 shows the correlations between different variables determined at the irrigated fields. The table shows that only two pairs of variables show larger absolute correlation coefficients: (i) SWC and ISWP, and (ii) SIPI and accumulated water depth, simply because SIPI was calculated based on incoming water depth and ET.
We could not find significant correlations between fruit production and other environmental variables. This shows that SWC and ISWP were still in a range without or very limited drought stress, so that production is not affected by those conditions. In addition, commercial fruit production was affected by other conditions like heavy rain and wind late in the season in 2016, which might have impacted the different fields to a different degree, and which adds additional noise in the relation between fruit production and other variables. Further variables of relevance are the citrus variety and the management by the farmers which differed between the fields and also might have affected production. In summary, it can be concluded that irrigation according the CLM-DA methodology did not reduce fruit production, and fruit production showed larger variations between fields related to other variables than SWC and ISWP.

\subsubsection{Soil water content - stem water potential relation}

As shown in Fig. 9, the soil water contents at $10 \mathrm{~cm}$ and $30 \mathrm{~cm}$ depth, show a significant linear correlation $(r=0.61)$ with integrated stem water potential. This implies that plant water stress can be monitored with help of soil water content measurements at $10 \mathrm{~cm}$ and $30 \mathrm{~cm}$ depth.

\subsubsection{Soil water content - incoming water depth relation}

The incoming water depth is the applied irrigation plus the precipitation and it is calculated for each field. Fig.10 shows that for the CLM and FAO-fields there is a relation between average SWC and incoming water depth. The incoming water depth is higher for fields with a low SWC, which illustrates that irrigation is especially needed for drier fields. It also illustrates that the irrigation amount was not too large, as the fields which are most intensively irrigated still have an average SWC smaller than other fields. This is not the case for the Farmer fields where average SWC is very high and the incoming water depth is also very high. It is clear that for those fields the high irrigation amounts resulted in high SWC reaching saturation.

\section{Conclusions and outlook}

During the irrigation campaign for the Picassent site (near Valencia, Spain) from July to October in 2015 and June to October in 2016, three different irrigation scheduling methods were tested for 10 citrus fields, including the CLM-DA method proposed in this paper, the FAO water balance model and a traditional method based on farmer's experience. The CLM-DA method combines model predictions by a land surface model, weather prediction and soil moisture data measured by capacitance probes. These information sources are optimally combined using sequential data assimilation, to predict drought stress for the next days and schedule irrigation accordingly.

The applied irrigation amounts were measured by a water meter. Stem water potential and citrus production indicating the possible water stress were also measured. The results illustrate the water saving potential of the CLM-DA method compared to traditional irrigation by farmers. The data from the different fields indicate that $18.5 \%$ less irrigation water was needed than the irrigation scheduling according the Farmer method. The stem water potential and deep soil water content data showed that during most of the irrigation period, CLM fields were not suffering from water stress. Although using less water than the farmer fields, no significant production loss was detected. The FAO method is also an efficient irrigation sched- 
Table 3

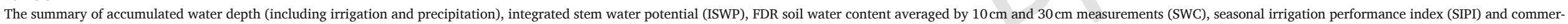
cial fruit production (Yield) for 3 CLM fields, 2 FAO fields and 2 Farmer fields in both year of 2015, 2016 (N.A. is no data).

\begin{tabular}{|c|c|c|c|c|c|c|c|c|c|c|}
\hline Fields & swC15 & SWC16 & ISWP15 & ISWP16 & water depth15 & water depth16 & SIPI 15 & SIPI 16 & Yield (ton/h)15 & Yield $($ ton $/ \mathrm{h}) 16$ \\
\hline & $\left(\mathrm{cm}^{3} / \mathrm{cm}^{3}\right)$ & $\left(\mathrm{cm}^{3} / \mathrm{cm}^{3}\right)$ & (MPa) & (MPa) & $(\mathrm{mm})$ & $(\mathrm{mm})$ & & & & \\
\hline CLM-A & 0.29 & 0.28 & -90.78 & -83.80 & 308.96 & 421.41 & 0.56 & 0.42 & 43.85 & 35.32 \\
\hline CLM-B & 0.3 & 0.32 & -93.06 & -92.01 & 312.42 & 311.57 & 0.79 & 0.81 & 38.78 & 14.54 \\
\hline CLM-C & 0.36 & 0.37 & -78.29 & -74.75 & 312.74 & 264.8 & 0.77 & 0.93 & 29.32 & 28.88 \\
\hline CLM-D & 0.21 & 0.25 & -88.94 & -104.71 & 370.35 & 329.44 & 0.55 & 0.64 & 11.55 & N.A. \\
\hline CLM-E & 0.22 & 0.23 & -90.70 & -86.49 & 354.9 & 380.86 & 0.56 & 0.53 & 19.54 & N.A. \\
\hline CLM-F & 0.34 & 0.35 & -60.66 & -68.98 & 398.76 & 419.95 & 0.5 & 0.49 & 27.53 & 25.85 \\
\hline FAO-A & 0.28 & 0.31 & -83.61 & -69.91 & 318.37 & 324.87 & 0.65 & 0.65 & 36.5 & 35.01 \\
\hline FAO-B & 0.2 & 0.22 & -92.54 & -83.88 & 361.15 & 348.48 & 0.63 & 0.67 & 50.37 & N.A. \\
\hline Farmer-A & 0.36 & 0.37 & -79.21 & -80.71 & 369.03 & 356.58 & 0.61 & 0.65 & 30.61 & 30.71 \\
\hline Farmer-B & 0.34 & 0.36 & -76.96 & -83.40 & 509.16 & 490.77 & 0.45 & 0.48 & 27.68 & 14.99 \\
\hline
\end{tabular}



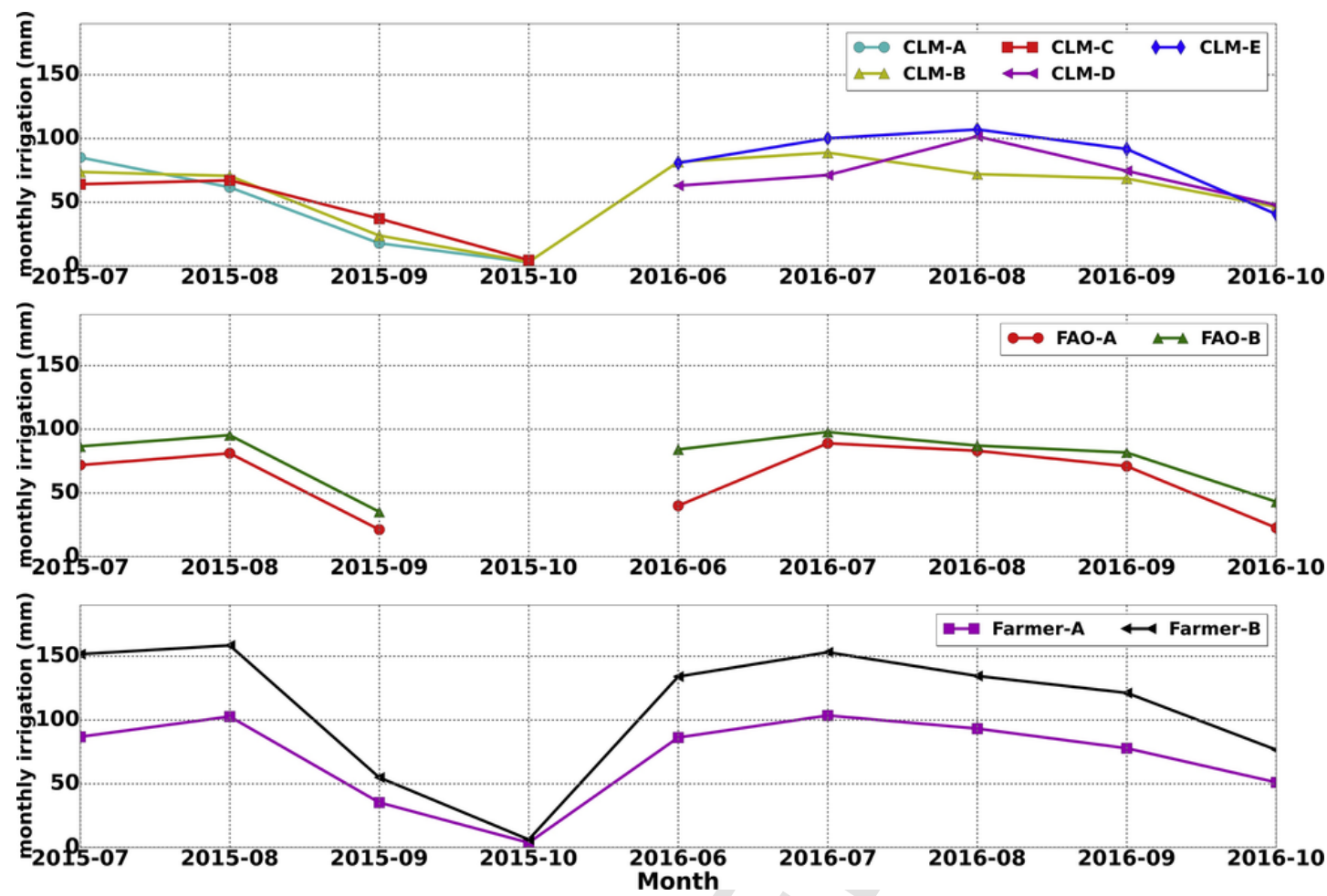

Fig. 7. Comparison of monthly applied irrigation amounts for the different fields according different irrigation scheduling methods in 2015 and 2016.
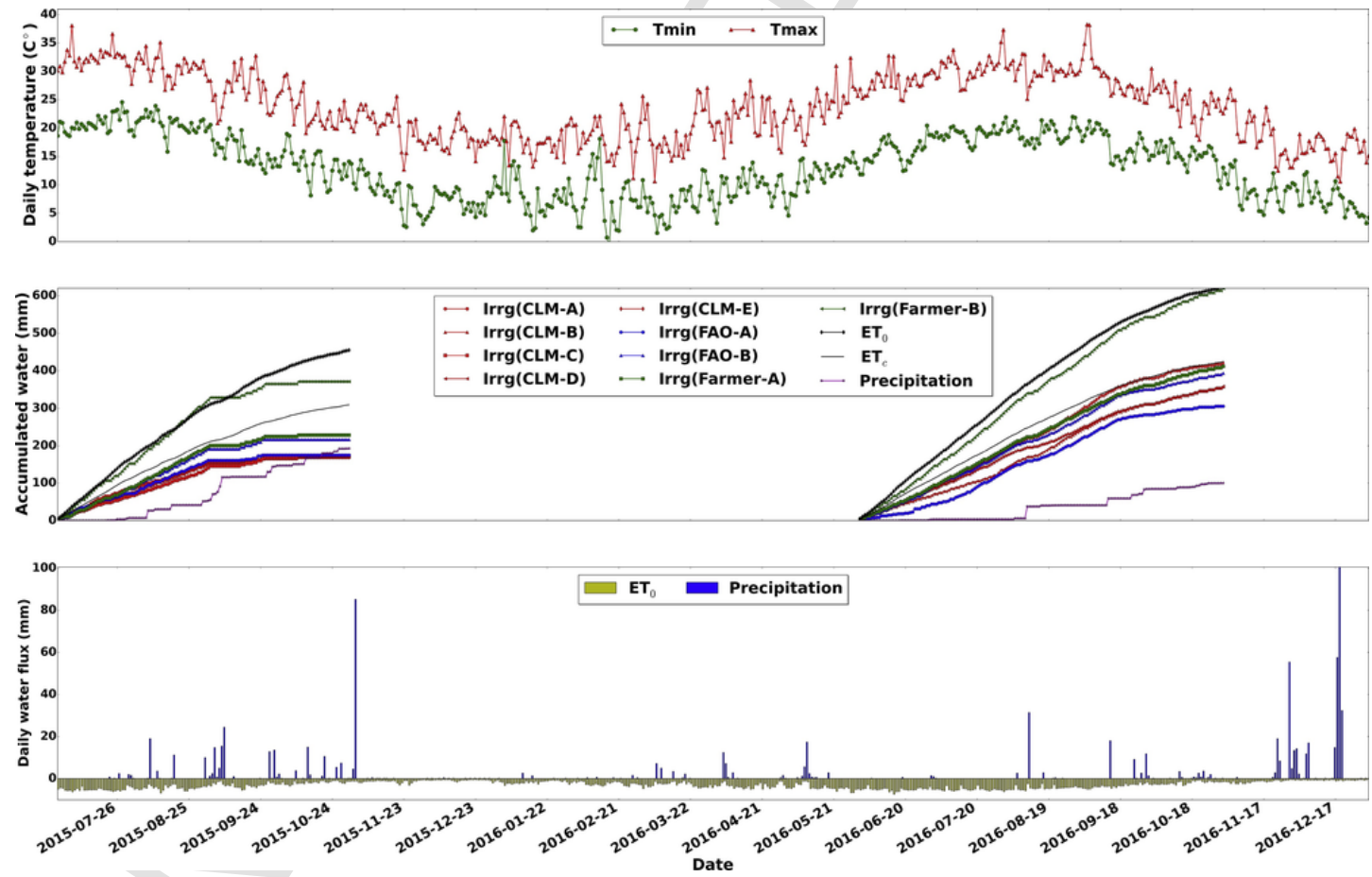

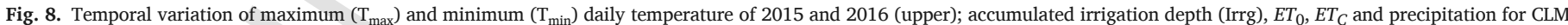
fields, FAO fields and other Farmer fields during the irrigation scheduling periods of 2015 and 2016 (middle); daily $E T_{0}$ and precipitation (bottom).

uling approach but it is highly dependent on site-specific empirical parameters.

A statistical analysis of all data collected in the field campaign revealed a positive correlation between SWC and integrated stem water potential data. This illustrates that SWC-data measured at $10 \mathrm{~cm}$ and $30 \mathrm{~cm}$ depth are useful to detect plant drought stress and can be used as basis to schedule irrigation. It was also found that for the CLM and FAO-fields, the applied amount of irrigation correlated negatively with SWC, illustrating that drier fields needed more irrigation and that it was the 
Table 4

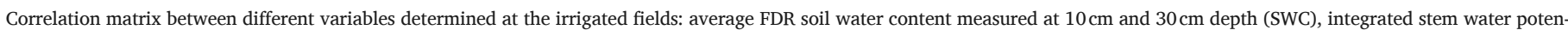
tial (ISWP), accumulated incoming water depth, seasonal irrigation performance index (SIPI) and commercial fruit production (Yield).

\begin{tabular}{|c|c|c|c|c|c|}
\hline & SWC & ISWP & water depth & SIPI & Yield \\
\hline SWC & 1.00 & 0.61 & -0.26 & 0.37 & -0.07 \\
\hline ISWP & 0.61 & 1.00 & 0.26 & -0.12 & -0.09 \\
\hline water depth & -0.26 & 0.26 & 1.00 & -0.87 & -0.11 \\
\hline SIPI & 0.37 & -0.12 & -0.87 & 1.00 & -0.03 \\
\hline yield & -0.07 & -0.09 & -0.11 & -0.03 & 1.00 \\
\hline
\end{tabular}

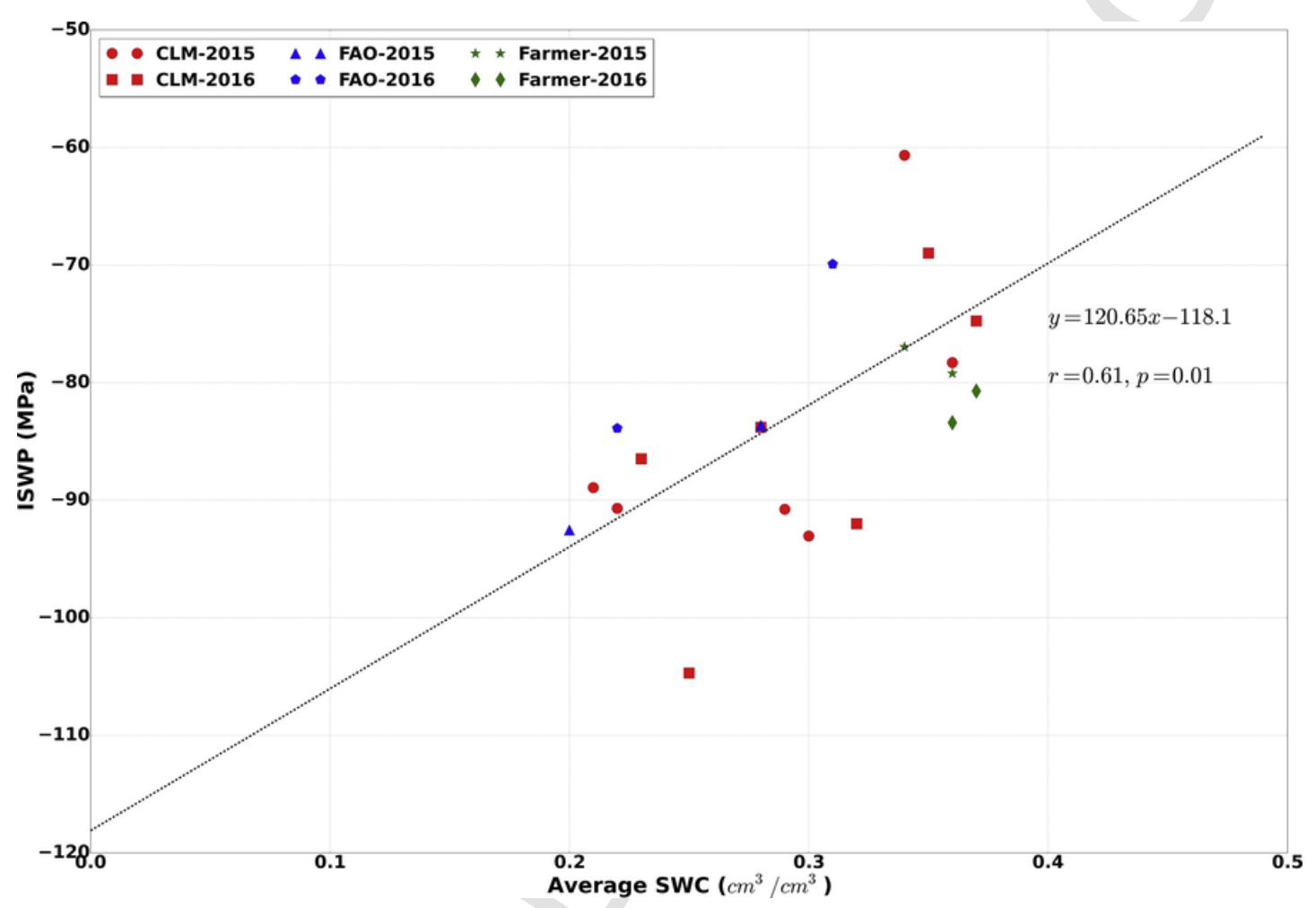

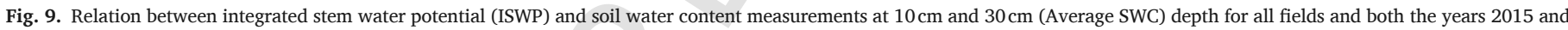
2016.

low SWC that governed irrigation amounts. On the contrary, for the fields that were irrigated according the Farmers method high average SWC was associated with very high irrigation amounts, indicating that for those fields the causal relation was different from the CLM- and FAO-fields; for the Farmer fields the high irrigation resulted in high SWC close to saturation. The statistical analysis also revealed no significant relation between SWC and ISWP on one hand and fruit production on the other hand, indicating that for the range of SWC and ISWP in this study, SWC and drought stress were not limiting factors for fruit production.

Comparing the CLM-DA, and FAO-methods, a similar performance was found in this study. It should be taken into account that the FAO-method was an established methodology for these fields and parameter settings were already tuned for this approach. Therefore the performance of the CLM-DA approach can be considered satisfying. The main differences between the two methods are the more complex and biophysically based model used in the CLM-DA method, the use of measurements in near real time to actualize the model state (while the FAO-method does not include those) and the use of a weather forecast. It is expected that the CLM-DA method will outperform the FAO-method if more measurements and better weather forecast data are available, if weather conditions are less stable and if the model is well calibrated on the basis of locally available data.

In summary, a rational, automated approach for irrigation scheduling was formulated with high potential in terms of integrating on-line data from sensors. The advantage of the CLM-DA method is automatic remote control, real time response, and the possibility to integrate all kinds of soil moisture and other data into a model. For example, this approach would also allow the integration of land surface temperature measured at high resolution by drones.

Nevertheless, the real-world application of this method is challenging. The accurate application of the calculated irrigation water to the fields was one of the challenges requiring intensive cooperation with farmers and continuous maintenance of the measurement infrastructure (e.g. soil moisture sensors). Irrigation scheduling could have been further improved with additional data which would have allowed the estimation of parameters specific for citrus trees as well as a better definition of the critical soil moisture threshold. 


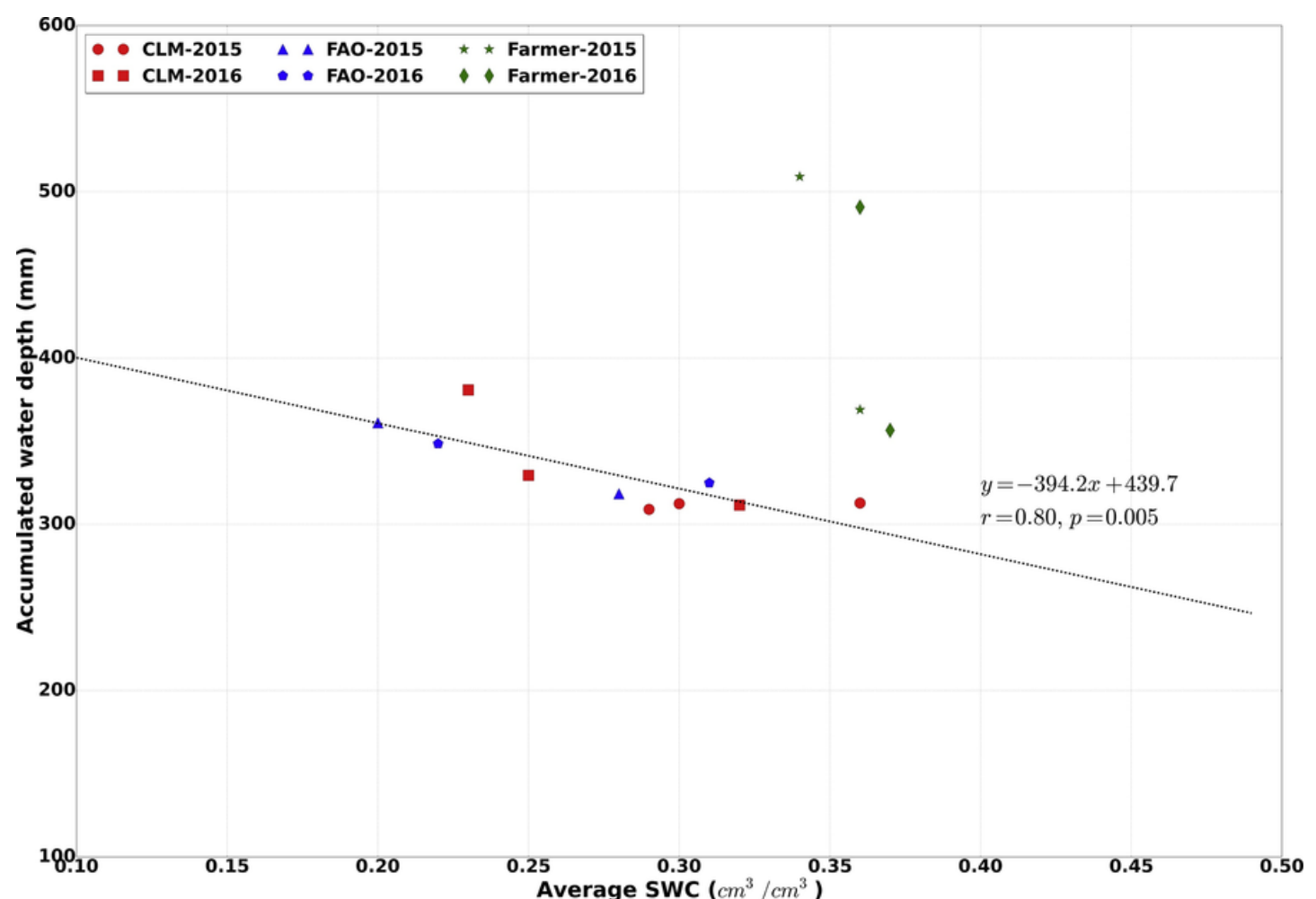

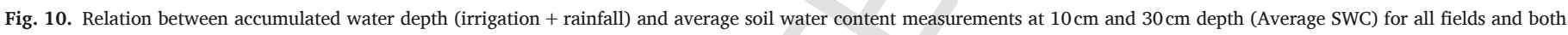
the years 2015 and 2016.

\section{Acknowledgements}

The first author of this paper was funded by a stipend from the Government of China (CSC scholarship). The support of the supercomputing facilities of Forschungszentrum Juelich (JURECA) is gratefully acknowledged. We are also thankful to our colleagues in IVIA and Universitat Politècnica de Valencia for the installation of soil moisture sensors and conducting stem water potential measurements.

\section{References}

Allen, R.G., Pereira, L.S., Raes, D., Smith, M., 1998. Crop Evapotranspiration-Guidelines for Computing Crop Water Requirements-FAO Irrigation and Drainage Paper No 56. FAO, Rome, Italy.

Autovino, D., Rallo, G., Provenzano, G., 2018. Predicting soil and plant water status dynamic in olive orchards under different irrigation systems with Hydrus-2D: model performance and scenario analysis. Agric. Water Manag. 203, 225-235.

Ballester, C., Castel, J., Intrigliolo, D., Castel, J., 2011. Response of Clementina de Nules citrus trees to regulated deficit irrigation. Yield components and fruit composition. Agric. Water Manag. 98, 1027-1032.

Ballester, C., Castel, J., Jiménez-Bello, M., Intrigliolo, D., Castel, J., 2014. Are sap flow and canopy temperature measurements useful alternatives to stem water potential for detecting plant water stress in citrus trees?. Acta Horticult. 51-57.

Barrett, J.H., Skogerboe, G.V., 1980. Crop production functions and the allocation and use of irrigation water. Agric. Water Manag. 3, 53-64.

Bausch, W.C., 1995. Remote sensing of crop coefficients for improving the irrigation scheduling of corn. Agric. Water Manag. 27, 55-68.

Blonquist, J., Jones, S.B., Robinson, D., 2006. Precise irrigation scheduling for turfgrass using a subsurface electromagnetic soil moisture sensor. Agric. Water Manag. 84, 153-165.

Brown, P.D., Cochrane, T.A., Krom, T.D., 2010. Optimal on-farm irrigation scheduling with a seasonal water limit using simulated annealing. Agric. Water Manag. 97, 892-900.
Castel, J.R., 2000. Water use of developing citrus canopies in Valencia, Spain. Proceedings International Society of Citriculture, IX Congress. 223-226.

Choné, X., Van Leeuwen, C., Dubourdieu, D., Gaudillère, J.P., 2001. Stem water potential is a sensitive indicator of grapevine water status. Ann. Bot. 87, 477-483.

Clawson, K.L., Blad, B.L., 1982. Infrared thermometry for scheduling irrigation of corn. Agron. J. 74, 311-316.

Dabach, S., Lazarovitch, N., Šimůnek, J., Shani, U., 2013. Numerical investigation of irrigation scheduling based on soil water status. Irrig. Sci. 31, 27-36.

Davis, S., Dukes, M., 2010. Irrigation scheduling performance by evapotranspiration-based controllers. Agric. Water Manag. 98, 19-28.

Evans, R.O., Sneed, R.E., Cassel, D.K., 1991. Irrigation Scheduling to Improve Water-and Energy-Use Efficiencies. NC Cooperative Extension Service.

Evensen, G., 2003. The ensemble Kalman filter: theoretical formulation and practical implementation. Ocean Dyn. 53, 343-367.

Fares, A., Alva, A.K., 2000. Evaluation of capacitance probes for optimal irrigation of citrus through soil moisture monitoring in an entisol profile. Irrig. Sci. 19, 57-64.

Fernández, J., Cuevas, M., 2010. Irrigation scheduling from stem diameter variations: a review. Agric. For. Meteorolo. 150, 135-151.

Fernández, J., Palomo, M., Diaz-Espejo, A., Clothier, B., Green, S., Girón, I., Moreno, F., 2001. Heat-pulse measurements of sap flow in olives for automating irrigation: tests, root flow and diagnostics of water stress. Agric. Water Manag. 51, 99-123.

García-Tejero, I., Romero-Vicente, R., Jiménez-Bocanegra, J., Martínez-García, G., Durán-Zuazo, V., Muriel-Fernández, J., 2010. Response of citrus trees to deficit irrigation during different phenological periods in relation to yield, fruit quality, and water productivity. Agric. Water Manag. 97, 689-699.

Han, X., Franssen, H.J.H., Montzka, C., Vereecken, H., 2014. Soil moisture and soil properties estimation in the Community Land Model with synthetic brightness temperature observations. Water Resour. Res. 50, 6081-6105.

Han, X., Franssen, H.-J., Rosolem, R., Jin, R., Li, X., Vereecken, H., 2015. Correction of systematic model forcing bias of CLM using assimilation of cosmic-ray neutrons and land surface temperature: a study in the Heihe Catchment, China. Hydrol. Earth Syst. Sci. 19, 615-629. 
Han, X., Franssen, H.-J.H., Bello, M.Á.J., Rosolem, R., Bogena, H., Alzamora, F.M., Chanzy, A., Vereecken, H., 2016. Simultaneous soil moisture and properties estimation for a drip irrigated field by assimilating cosmic-ray neutron intensity. J. Hydrol. 539, 611-624.

Hunt, B.R., Kostelich, E.J., Szunyogh, I., 2007. Efficient data assimilation for spatiotemporal chaos: a local ensemble transform Kalman filter. Phys. D: Nonlinear Phenom. 230, 112-126.

Iglesias, A., Garrote, L., 2015. Adaptation strategies for agricultural water management under climate change in Europe. Agric. Water Manag. 155, 113-124.

Irmak, A., Kamble, B., 2009. Evapotranspiration data assimilation with genetic algorithms and SWAP model for on-demand irrigation. Irrig. Sci. 28, 101-112.

Jiménez-Bello, , Castel, J.R., Testi, L., Intrigliolo, D.S., 2015. Assessment of a remote sensing energy balance methodology (SEBAL) using different interpolation methods to determine evapotranspiration in a Citrus Orchard. IEEE J. Sel. Top. Appl. Earth Observ. Remote Sens. 8, 1465-1477.

Jones, H.G., 2004. Irrigation scheduling: advantages and pitfalls of plant-based methods. J. Exp. Bot. 55, 2427-2436.

Lorite, I., Ramírez-Cuesta, J., Cruz-Blanco, M., Santos, C., 2015. Using weather forecast data for irrigation scheduling under semi-arid conditions. Irrig. Sci. 33, 411-427.

McLaughlin, D., Kinzelbach, W., 2015. Food security and sustainable resource management. Water Resour. Res. 51, 4966-4985.

Miralles, D., Holmes, T., De Jeu, R., Gash, J., Meesters, A., Dolman, A., 2011. Global land-surface evaporation estimated from satellite-based observations. Hydrol. Earth Syst. Sci. 15, 453 .

Miyoshi, T., Yamane, S., Enomoto, T., 2007. Localizing the error covariance by physical distances within a local ensemble transform Kalman filter (LETKF). SOLA 3, 89-92.

Moran, M., Clarke, T., Inoue, Y., Vidal, A., 1994. Estimating crop water deficit using the relation between surface-air temperature and spectral vegetation index. Remote Sens. Environ. 49, 246-263.

Moriana, A., Girón, I., Martín-Palomo, M., Conejero, W., Ortuño, M., Torrecillas, A., Moreno, F., 2010. New approach for olive trees irrigation scheduling using trunk diameter sensors. Agric. Water Manag. 97, 1822-1828.

Oleson, K.W., Lawrence, D.M., Gordon, B., Flanner, M.G., Kluzek, E., Peter, J., Levis, S Swenson, S.C., Thornton, E., Feddema, J., 2010. Technical Description of Version 4.0 of the Community Land Model (CLM).

Pardossi, A., Incrocci, L., 2011. Traditional and new approaches to irrigation scheduling in vegetable crops. HortTechnology 21, 309-313.

Peters, R.T., Desta, K., Nelson, L., 2013. Practical Use of Soil Moisture Sensors and Their Data for Irrigation Scheduling. State University Extension, Washington.

Playán, E., Mateos, L., 2006. Modernization and optimization of irrigation systems to increase water productivity. Agric. Water Manag. 80, 100-116.

Provenzano, G., 2007. Using HYDRUS-2D simulation model to evaluate wetted soil volume in subsurface drip irrigation systems. J. Irrig. Drain. Eng. 133, 342-349.

Pulido-Calvo, I., Gutiérrez-Estrada, J.C., 2009. Improved irrigation water demand forecasting using a soft-computing hybrid model. Biosyst. Eng. 102, 202-218.
Rallo, G., Agnese, C., Minacapilli, M., Provenzano, G., 2011. Comparison of SWAP and FAO agro-hydrological models to schedule irrigation of wine grapes. J. Irrig. Drain. Eng. 138, 581-591.

Rallo, G., González-Altozano, P., Manzano-Juárez, J., Provenzano, G., 2017. Using field measurements and FAO-56 model to assess the eco-physiological response of citrus orchards under regulated deficit irrigation. Agric. Water Manag. 180, 136-147.

Reichle, R.H., 2008. Data assimilation methods in the earth sciences. Adv. Water Resour. $31,1411-1418$

Sammis, T., Sharma, P., Shukla, M., Wang, J., Miller, D., 2012. A water-balance drip-irrigation scheduling model. Agric. Water Manag. 113, 30-37.

Scanlon, B.R., Faunt, C.C., Longuevergne, L., Reedy, R.C., Alley, W.M., McGuire, V.L., McMahon, P.B., 2012. Groundwater depletion and sustainability of irrigation in the US high plains and Central Valley. Proc. Natl. Acad. Sci. U. S. A. 109, 9320-9325.

Sdoodee, S., Somjun, J., 2008. Measurement of stem water potential as a sensitive indicator of water stress in neck orange (Citrus reticulata Blanco). Sonklanakarin J. Sci. Technol. 30, 561.

Shang, S., Mao, X., 2006. Application of a simulation based optimization model for winter wheat irrigation scheduling in North China. Agric. Water Manag. 85, 314-322.

Smajstrla, A., Locascio, S., 1996. Tensiometer-controlled, drip-irrigation scheduling of tomato. Appl. Eng. Agric. 12, 315-319.

Syvertsen, J., 1982. Minimum leaf water potential and stomatal closure in citrus leaves of different ages. Ann. Bot. 49, 827-834.

Syvertsen, J., Smith Jr., M., Allen, J., 1981. Growth rate and water relations of citrus leaf flushes. Ann. Bot. 47, 97-105.

Ticlavilca, A.M., Mckee, M., Walker, W.R., 2013. Real-time forecasting of short-term irrigation canal demands using a robust multivariate Bayesion learning model. Irrig. Sci. $31,151-167$.

Turner, N.C., 1981. Techniques and experimental approaches for the measurement of plant water status. Plant Soil 58, 339-366.

Velez, J., Intrigliolo, D., Castel, J., 2007. Scheduling deficit irrigation of citrus trees with maximum daily trunk shrinkage. Agric. Water Manag. 90, 197-204.

Vereecken, H., Burauel, P., Groeneweg, J., Klumpp, E., Mittelstaedt, W., Putz, T., van der Kruk, J., Vanderborght, J., Wendland, F., 2009. Research at the Agrosphere Institute: from the process scale to the catchment scale. Vadose Zone J. 8, 664-669.

Vörösmarty, C.J., Green, P., Salisbury, J., Lammers, R.B., 2000. Global water resources: vulnerability from climate change and population growth. Science 289, 284-288.

Wardlaw, R., Bhaktikul, K., 2004. Application of genetic algorithms for irrigation wate scheduling. Irrig. Drain. 53, 397-414.

Zeng, X., 2001. Global vegetation root distribution for land modeling. J. Hydrometeorol. $2,525-530$.

Zreda, M., Shuttleworth, W.J., Zeng, X., Zweck, C., Desilets, D., Franz, T., Rosolem, R. 2012. COSMOS: the COsmic-ray soil moisture observing system. Hydrol. Earth Syst. Sci. 16, 4079-4099. 